\title{
CONCURRENT MULTI-SCALE MODELING OF A TRANSMISSION TOWER STRUCTURE AND ITS EXPERIMENTAL VERIFICATION
}

\author{
F.Y. Wang*, Y.L. Xu and S. Zhan \\ Department of Civil and Environmental Engineering, The Hong Kong Polytechnic University, Kowloon, Hong Kong \\ *(Corresponding author: E-mail fy11423@sina.com)
}

Received: 16 February 2016; Revised: 21 June 2016; Accepted: 3 September 2016

\begin{abstract}
The interruption of electrical service due to failure of transmission tower structures can have devastating economic and social consequences. The current method for analyzing transmission tower structures is often to treat the angle members of the tower as either pin-ended truss elements or fix-ended beam elements. This approach ignores the effects of joint flexibility, local geometric and material nonlinearity, bolt slippage and deformation, making the structural analysis and design of the tower inadequate. In an effort to improve the structural analysis of transmission tower structures, this study aims at developing a multi-scale modeling method for transmission tower structures, in which critical joints of the tower are modeled using solid elements in a great detail while other members are modeled with common beam elements. The critical joint model includes gusset plates, angle members and bolts. The effects of local geometric and material nonlinearity and the contact problem between the bolts, plates and angles are all taken into consideration. New multi-point constraints for beam-to-solid connections at interface developed by the authors are used to couple the critical local joint model with the beam elements to form a multi-scale model of the tower. To verify the multi-scale modeling method, a physical model of a transmission tower structure was constructed and tested. The displacement and strain response of the tower model measured from the static tests are compared with the numerical results. The dynamic characteristics of the tower model identified from the dynamic tests are also compared with the numerical results. The comparative results show that the multi-scale modeling method is feasible and accurate for simultaneously predicting both global and local responses as well as estimating dynamic characteristics of the transmission tower structure.
\end{abstract}

Keywords: Multi-scale modeling, transmission tower, bolted connection, new multi-point constraints, experiment, comparison

DOI: $10.18057 /$ IJASC.2017.13.3.4

\section{INTRODUCTION}

Transmission towers are vital components of transmission lines. Most of transmission tower structures are constructed by thin-walled angle members that are eccentrically connected to each other by bolts directly or through gusset plates. In the global analysis of a transmission tower, its angle members are often modeled using either pin-ended truss elements or fix-ended beam elements to form a global finite element (FE) model for the tower [1-5]. Nevertheless, this kind of global model ignores the effects of joint flexibility, local geometric and material nonlinearity, bolt slippage and deformation on the global behavior of the tower, which make the structural analysis and design of the tower inadequate. To overcome this problem, the joints in the global FE model are sometime modified as semi-rigid linear or nonlinear joints to consider joint effects on the global behavior of the tower [6-9]. In this regard, Rao and Kalyanaraman [5] presented a non-linear analysis method for lattice towers in consideration of member eccentricity, material non-linearity and rotational rigidity of joints. Ungkurapinan et al. [10] developed some formulas to describe joint slips based on the relevant test data. However, the use of semi-rigid joints cannot guarantee the accuracy of the analysis because there are a variety of joints, in terms of the number of bolts and the shape of gusset plates, making it difficult to determine the structural parameters for semi-rigid joints. For the analysis and design of local joints of the tower, the local joints are then modeled 
using solid or shell elements [11-14]. The boundary conditions of a local joint model are often assigned by using the information extracted from the global analysis of the global FE model of the tower. This approach for the analysis and design of the global structure and local joints may be called the information-passing multi-scale method [15]. However, it is difficult to determine dynamic boundary conditions for the local joint model, and inaccurate boundary conditions will lead to large error in the calculated structural responses. Furthermore, if the solid and shell elements are used to model all the members and joints of the tower, the computational size for the global structure analysis will be too large to be implemented.

Recently, the concurrent multi-scale method is proposed to model large civil structures [15-17], in which the local joints are simulated with shell or plate elements in much detail while other components in the structure are simulated with beam or truss elements. Different scales of elements are then coupled to form a multi-scale FE model. Such a concurrent multi-scale simulation can simultaneously capture not only the global structural behavior but also the local joint behavior without a huge computation cost. The key issue of concurrent multi-scale modeling is the coupling of mixed-dimensional elements (beam, shell and solid) at their interfaces. Broadly speaking, there are two major coupling methods currently available: volume coupling and surface coupling [18]. Volume coupling refers to a region in which different models co-exist and it is usually realized using the Arlequin method [19, 20]. The Arlequin method is best suited for coupling different physical models such as continuum particles [21, 22] among others. In surface coupling, there is no overlapping of different models and different models can be coupled using one of the following methods: (a) transition element method; and (b) multipoint constraint (MPC) method. Transition elements can be used for shell-solid transition [23], beam-solid transition [24, 25], and beam-shell transition [26]. Unfortunately, the transition elements have not been widely adopted because of its limitations. Transition elements can only be used to a one-to-one coupling of elements and different element transitions require different formulations, which make it difficult and impractical for a commercial FE code. The MPC method is attractive for mixed-dimensional coupling by imposing constraint equations for nodal displacements at the interface. The MPC method can be used for static and dynamic analysis of linear or nonlinear structures [27-29]. In commercial FE software, MPC can be easily used for coupling different types of elements. Nevertheless, although there are several types of MPC in existing FE software, inaccurate constraint equations due to inappropriate assumptions may result in stress disturbance at the interface. The authors recently developed a reliable method for constructing appropriate MPC to guarantee the displacement compatibility and stress equilibrium at the multi-scale interface [30].

With all the aforementioned, this study aims at developing a concurrent multi-scale modeling method for transmission tower structures, in which critical joints of the tower are modeled using solid elements in much detail while other angle members are modeled with common beam elements. The detailed model for a critical joint includes gusset plates, angle members and bolts. The effects of local geometric and material nonlinearity and the contact problem between the bolts, plates and angles are all taken into consideration. The new multi-point constraints for beam-to-solid interface connections developed by the authors are used to ensure the computational accuracy and efficiency at interfaces so that the critical local joint models can be coupled with the common tower model to form a multi-scale model of the tower. To verify the proposed multi-scale modeling method, a physical model of a transmission tower structure at a length scale of 1:10 was constructed and tested. The displacements and strains of the tower model measured from the static tests are compared with the numerical results obtained by the multi-scale modeling method. The dynamic characteristics of the tower identified from the dynamic tests are also compared with the numerical results. 


\section{A PHYSICAL MODEL OF A TRANSMISSION TOWER STRUCTURE}

In order to verify the accuracy of multi-scale modeling and analysis of a transmission tower structure, a physical model of a transmission tower structure was built. The prototype of the tower is a cup-type and straight-line tower, having a $50.50 \mathrm{~m}$ height and a $22.02 \mathrm{~m}$ width. It is used in $500 \mathrm{kv}$ networks of the state grid of China, suitable for the areas with heavy icing or high lightning incidence. The tower is assembled from 23 types of angle members, which are connected to each other at joint plates with bolts. In consideration of the physical modeling of bolts and joint plates as well as the availability of laboratory space, the length ratio of the reduced-scale model to the prototype was selected as 1:10. The stainless steel was chosen as the material to make angle members and joint plates. The scaled model was designed and fabricated following the geometric similarity laws as close as possible. In order to guarantee the precision of local joints of the transmission tower, the components of local joints, such as bolts and gusset plate, were also fabricated according to the length ratio. The angle members and gusset plates were tailor-made in the factory by using the stainless steel plates. The completed tower model had 930 angle members, 402 gusset plates, and 3649 bolts. The completed physical model of the tower and a local joint are shown in Figure 1(a) and Figure 1(b) respectively. The tower model was finally connected to the four steel bases by bolts at its four legs and the four steel bases were in turn firmly fixed on a large concrete block ( see Figure 1(c) ) while the concrete block was connected to the strong floor of the laboratory. Both static and dynamic tests were performed to provide test data for verifying the numerical results from multi-scale analysis.

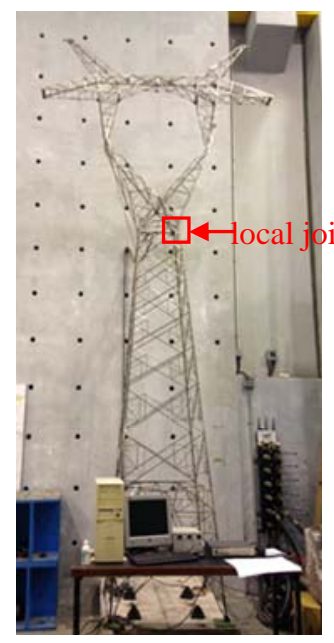

(a) global tower model

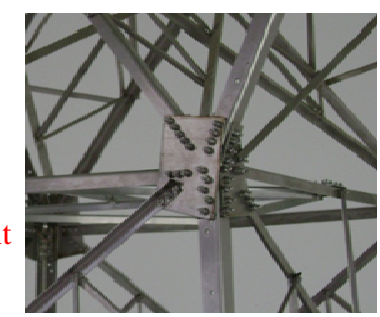

(b) local joint

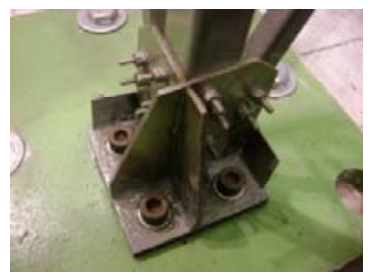

(c) base joint

Figure 1. Physical Model of a Transmission Tower

\section{MULTI-SCALE MODELING OF THE TRANSMISSION TOWER}

For a transmission tower, there are many complex problems to deal with in the process of multi-scale modeling, such as the interface coupling of mix-dimensional elements and the contact problem between bolts and plates. Most of the commercial FE software has the features of dealing with these problems. It is therefore more convenient to build the multi-scale model of the test transmission tower using commercial FE software. The FE software ANSYS is used in this study together with the self-written supplemental programs for multi-scale modeling and analysis of the transmission tower structure. 
The main purpose of the multi-scale modeling and analysis of the transmission tower is to obtain its global and local responses simultaneously. For the sake of a clear demonstration of the proposed method, only one typical and most important joint between the crank arm and the tower body is selected to construct a detailed local FE joint model. The selected joint consists of 9 angle members of a shortened length, 3 gusset plates and 40 bolts. In order to accurately simulate the bolt connection, all the components of the joint are modeled using solid elements. Consequently, the 20-node SOLID95 elements of higher order, which can simulate irregular shapes with no loss in accuracy, are used to model angle members, gusset plate and bolts of the selected joint. Apart from this joint, all other joints (including the base joints) are modeled as rigid joints and all other angle members of the tower are modeled using beam elements, which are actually the BEAM188 elements in the FE software ANSYS. Like the conventional modeling, the joint eccentricity is neglected when the beam elements and rigid joints are used. The completed multi-scale model of the transmission tower is shown in Figure 2 together with the local joint model. It is noted that there is an interface for each of 9 angle members used in the joint between the global tower model and the local joint model.

One of the most complex problems in the local modeling of the joint is the interaction between different components for bolt connection, such as the contact between the bolt and the angle member, the contact between the bolt and the gusset plate, and the contact between the angle member and the gusset plate. These interactions are achieved by using the contact elements TARGE170 and CONTA174 of surface-to-surface type, which avoid one element to penetrate into another. Furthermore, these contact elements can simulate friction forces between the two surfaces according to the Mohr-Coulomb law. The friction forces depend on the smoothness of the surfaces and the pretension forces of the bolts. The value of the coefficient of friction is taken as 0.3 in this study. The pretension force elements PRETS179 are used to simulate the pre-tightening of the bolts. In terms of stiffness, the interaction between the angle member and gusset plate is defined as the flexible-to-flexible contact problem because both of them are of equal stiffness. The interaction between the bolt and the gusset plate or angle member is defined as the rigid-to-flexible contact problem because the bolt is considered stiffer than the plate or the angle member. In the contact problem concerned, the first part refers to the target and the second part to the contact surface. For a rigid-to-flexible contact, the target surface is always more stiff and the contact surface is always less stiff. The contact elements are applied to the joint components by the Augmented Lagrange formulation, and the contact stiffness is updated during equilibrium iteration. Figure 3 shows the contact interaction between angle member, gusset plate and bolt of the local joint. Finally, the interface of the angle member between the solid and beam elements is coupled by using the constraint method recently developed by the authors [30]. The new constraint method is briefly described in the following section for the sake of completion and easy understanding.

\section{INTERFACE COUPLING OF MIXED-DIMENSIONAL ELEMENTS}

Taking the interface coupling of beam-to-solid elements as an example, the displacement constraint can be established in the sense that the displacement of beam at the interface equals to the generalized displacement of solid at the interface, which can be expressed as

$$
\boldsymbol{c}\left(\boldsymbol{u}_{B}, \boldsymbol{u}_{S}\right)=\boldsymbol{u}_{B}-\boldsymbol{C} \boldsymbol{u}_{S}=0
$$

where $\boldsymbol{u}_{B}$ and $\boldsymbol{u}_{S}$ are the nodal displacement vector of beam and solid, respectively, at the interface; $\boldsymbol{C}$ is the weighting coefficient matrix of the displacement constraint equation. 


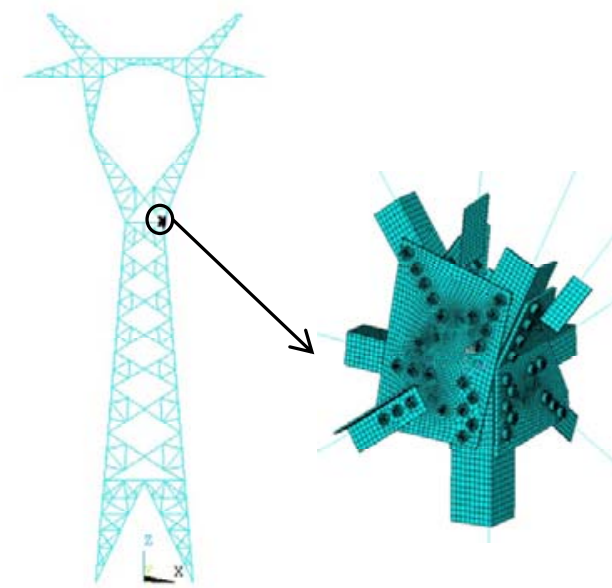

$\begin{array}{ll}\text { (a) global tower model } & \text { (b) local joint }\end{array}$

Figure 2. Multi-scale Model of a Transmission Tower

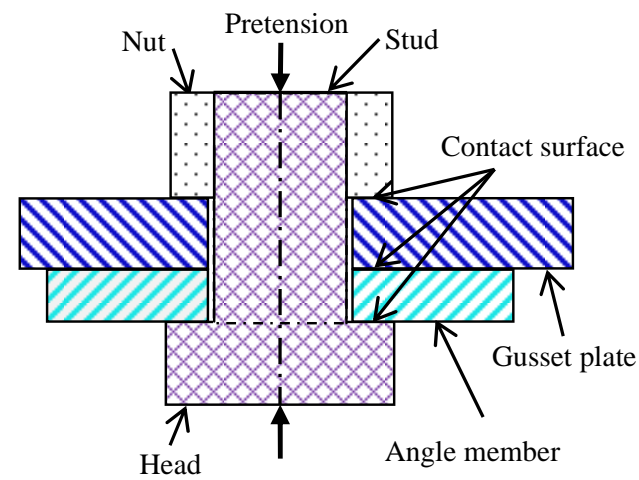

Figure 3. Contact between Angle Member, Gusset Plate and Bolt of the Local Joint

The variation of Eq. 1 can be expressed as

$\delta \boldsymbol{c}\left(\boldsymbol{u}_{B}, \boldsymbol{u}_{S}\right)=\delta \boldsymbol{u}_{B}-\boldsymbol{C} \delta \boldsymbol{u}_{S}=0$

in which $\delta \boldsymbol{u}_{B}$ and $\delta \boldsymbol{u}_{S}$ are the virtual displacement vectors at the interface of beam and solid, respectively.

The sum of virtual work done by the corresponding forces at the interface of the two types of elements shall be zero.

$\delta \mathrm{W}_{B}+\delta \mathrm{W}_{\mathrm{S}}=0$

where $\delta \mathrm{W}_{B}$ and $\delta \mathrm{W}_{S}$ are the virtual works done by the nodal forces at the interface of beam and solid, respectively.

The virtual works done by the nodal forces at the interface of solid and beam are respectively

$\delta \mathrm{W}_{S}=\delta \boldsymbol{u}_{\mathrm{S}}^{\mathrm{T}} \boldsymbol{F}_{S}$

$\delta \mathrm{W}_{B}=\delta \boldsymbol{u}_{B}^{\mathrm{T}} \boldsymbol{F}_{B}$

where $\boldsymbol{F}_{S}$ and $\boldsymbol{F}_{B}$ are the nodal forces at the interface of solid and beam, respectively.

By substituting Eq. (4) into Eq. (3), we have the following equation

$\delta \boldsymbol{u}_{S}^{\mathrm{T}} \boldsymbol{F}_{S}+\delta \boldsymbol{u}_{B}^{\mathrm{T}} \boldsymbol{F}_{B}=0$ 
From Eq. 2, we have $\delta \boldsymbol{u}_{B}=\boldsymbol{C} \delta \boldsymbol{u}_{S}$. Eq. 5 then becomes

$$
\delta \boldsymbol{u}_{S}^{\mathrm{T}} \boldsymbol{F}_{S}+\delta \boldsymbol{u}_{S}^{\mathrm{T}} \boldsymbol{C}^{\mathrm{T}} \boldsymbol{F}_{B}=0
$$

Eq. 6 shall hold for any arbitrary virtual displacements, and thus the nodal forces shall be related by $\boldsymbol{F}_{S}=-\boldsymbol{C}^{\mathrm{T}} \boldsymbol{F}_{B}$

Eq. 7 gives the constraint equation of nodal forces of beam and solid at the interface. The matrix $C^{T}$ can be regarded as a distribution matrix to distribute the forces or moment at the beam node to the solid nodes at the interface, and one column of the distribution matrix $C^{\mathrm{T}}$ actually corresponds to the nodal forces of the solid at the interface under unit force or moment. Therefore, a numerical method has been developed to calculate the nodal forces of the solid by applying unit force or moment and finally to construct the distribution matrix $\boldsymbol{C}^{\mathrm{T}}$ [30]. Once distribution matrix is obtained, the displacement constraint equation can be easily found by the transpose of the distribution matrix.

In this study, the interface coupling of mixed-dimensional elements is achieved by imposing the constraint equations in the commercial software ANSYS [31] using the CE command. The FE model of local joint and the interface coupling between the beam and solid elements are shown in Figure 4.

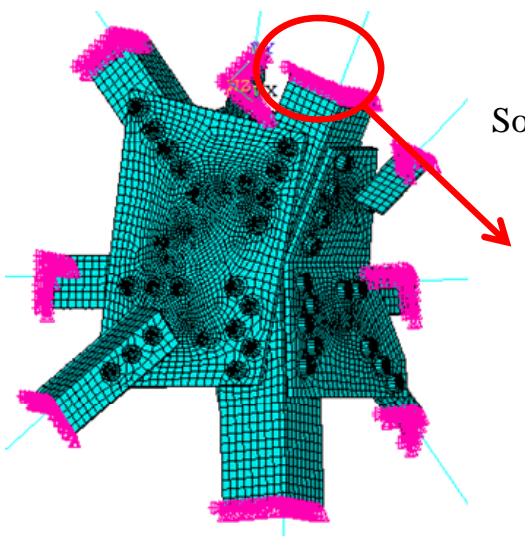

(a) joint model

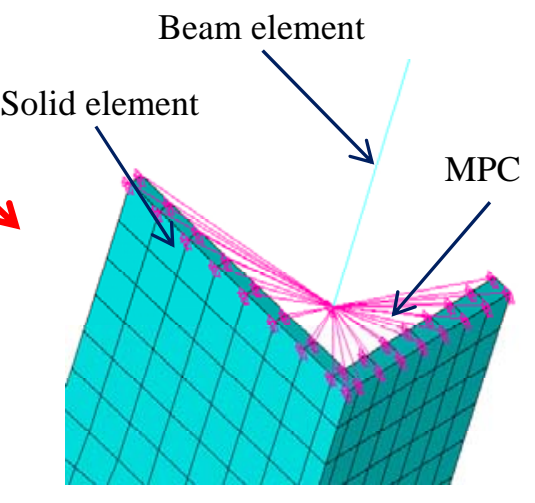

(b) interface coupling

Figure 4. Finite Element Model of Local Joint and Interface Coupling

\section{VERIFICATION OF MULTI-SCALE MODELING METHOD}

\subsection{Test Cases}

A static test was first carried out on the physical model of the transmission tower fixed on the ground of the laboratory. A horizontal concentrated load was applied at the middle of cross arm of the transmission tower in the longitudinal direction (transmission line direction) as shown in Figure 5 .

The concentrated load was increased step by step up to $60 \mathrm{~N}$ at an incremental load of $10 \mathrm{~N}$. A total of 3 displacement transducers (D1-D3) and 26 strain gauges (S1-S26) were used to measure the static responses of the tower due to the concentrated load. The measurement results of static displacements and stains are listed in Table 1-Table 3. 


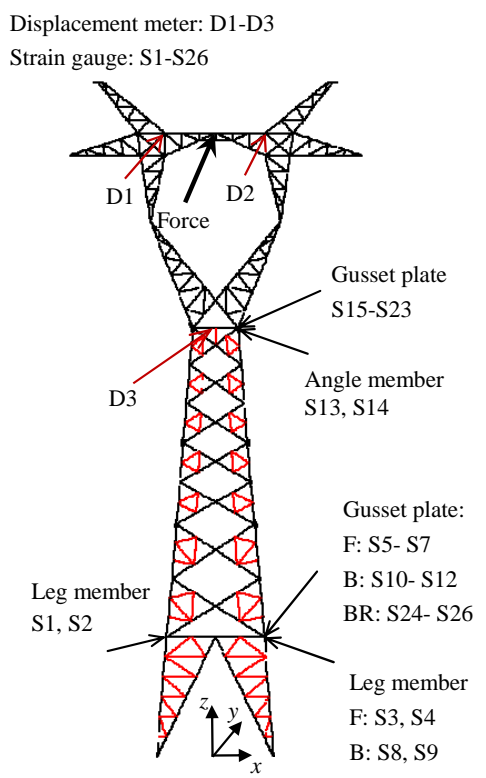

Figure 5. Locations of Loading Point and Measurment Points in Static Test

Table 1. Comparison of Static Displacement Responses (mm)

\begin{tabular}{ccccccc}
\hline Measurement point & Load $(\mathrm{N})$ & Measured displacement & Beam model & Error (\%) & Multi-scale model & Error (\%) \\
\hline \multirow{5}{*}{ D1 } & 10 & 0.224 & 0.228 & 1.8 & 0.228 & 1.8 \\
& 20 & 0.468 & 0.457 & -2.4 & 0.457 & -2.4 \\
& 30 & 0.701 & 0.685 & -2.3 & 0.686 & -2.1 \\
& 40 & 0.915 & 0.913 & -0.2 & 0.915 & 0.0 \\
& 50 & 1.132 & 1.142 & 0.9 & 1.144 & 1.1 \\
& 60 & 1.378 & 1.370 & -0.6 & 1.373 & -0.4 \\
\hline D2 & 10 & 0.223 & 0.228 & 2.2 & 0.228 & 2.2 \\
& 20 & 0.462 & 0.456 & -1.3 & 0.458 & -0.9 \\
& 30 & 0.689 & 0.684 & -0.7 & 0.688 & -0.1 \\
& 40 & 0.907 & 0.911 & 0.4 & 0.917 & 1.1 \\
& 50 & 1.130 & 1.139 & 0.8 & 1.147 & 1.5 \\
& 60 & 1.377 & 1.367 & -0.7 & 1.377 & 0.0 \\
\hline D3 & 10 & 0.059 & 0.063 & 6.8 & 0.061 & 3.4 \\
& 20 & 0.120 & 0.126 & 5.0 & 0.123 & 2.5 \\
& 30 & 0.181 & 0.189 & 4.4 & 0.184 & 1.7 \\
& 40 & 0.247 & 0.252 & 2.0 & 0.245 & -0.8 \\
& 50 & 0.305 & 0.315 & 3.3 & 0.307 & 0.7 \\
& 60 & 0.367 & 0.378 & 3.0 & 0.368 & 0.3 \\
\hline
\end{tabular}

Table 2. Comparison of Static Strain on the Main Member of the Tower Leg $\left(10^{-6}\right)$

\begin{tabular}{cccccc}
\hline Gauge number & Measured strain & Beam model & Error (\%) & Multi-scale model & Error (\%) \\
\hline S1 & 21.59 & 22.33 & 3.43 & 22.34 & 3.47 \\
S2 & 26.55 & 25.73 & 3.09 & 25.73 & 3.09 \\
S3 & 26.93 & 25.69 & 4.60 & 25.68 & 4.64 \\
S4 & 22.52 & 22.33 & 0.84 & 22.33 & 0.84 \\
S8 & -21.09 & -22.30 & 5.74 & -22.31 & 5.76 \\
S9 & -25.41 & -25.71 & 1.18 & -25.71 & 1.18 \\
\hline
\end{tabular}


Table 3. Comparison of Static Strain on the Local Joint $\left(10^{-6}\right)$

\begin{tabular}{cccccc}
\hline Gauge number & Measured strain & Beam model & Error (\%) & Multi-scale model & Error (\%) \\
\hline S13 & 34.10 & 28.83 & 15.45 & 34.62 & 1.52 \\
S14 & 12.27 & 24.48 & 99.51 & 11.70 & 4.65 \\
S15, S16, S17 & 21.90 & - & - & 23.63 & 7.90 \\
S18, S19, S20 & 8.20 & - & - & 8.82 & 7.56 \\
\hline
\end{tabular}

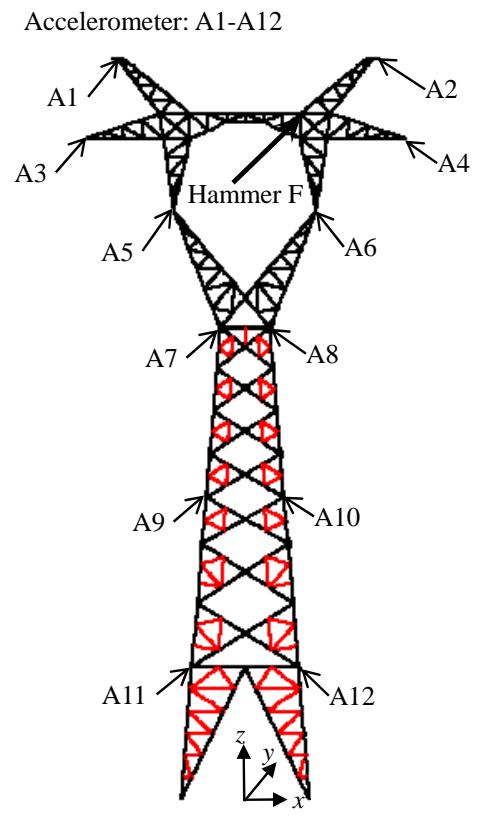

(a) test in longitudinal direction
Accelerometer: A13-A18

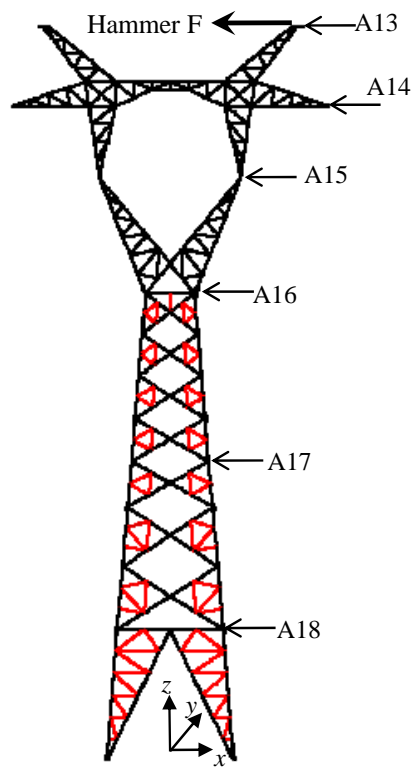

(b) test in transverse direction

Figure 6. Locations of Accelerometers in Hammer Test

After the static tests were completed, the hammer tests were then carried out on the physical model of the transmission tower to identify the natural frequencies and modal shapes of the tower. Accelerometers were accordingly arranged in both longitudinal and transverse directions and their locations are shown in Figure 6. The measured first 9 natural frequencies are listed in Table 4.

\subsection{Comparison of Static Displacements and Strains}

In addition to the multi-scale model of the tower, the beam model of the tower is also built in a conventional way, in which the BEAM188 elements and the rigid joints are used without considering joint eccentricity. Both the beam model and multi-scale model of the transmission tower are used to calculate the strain and displacement responses of the tower under the concentrated load, and the results from the multi-scale model and the beam model are then compared with those from the static tests. Table 1 lists the displacement values against concentrated load for the multi-scale model, the beam model, and the physical model. The force-displacement relationships of the measurement points D1, D2 and D3 are shown in Figure 7. It can be seen that the force-displacement relationship is almost linear within the applied load range. For D1 and D2, the results from the beam model and the multi-scale model are almost the same. The results obtained from the multi-scale model are also very close to the test results. For D3, the displacements obtained from the multi-scale model are closer to the test results than the results from the beam model. In consideration of the locations of D1, D2 and D3 as shown in Figure 5, D1 and D2 locate on the cross arm of the tower and they are far away from the local joint modeled by 
the solid elements. Therefore, the displacement results of D1 and D2 from the multi-scale model and the beam model are very close. On the other hand, D3 locates on the angle member that is connected to the local joint modeled by the solid elements. The multi-scale model can therefore improve the accuracy of the displacement of the angle member at D3.

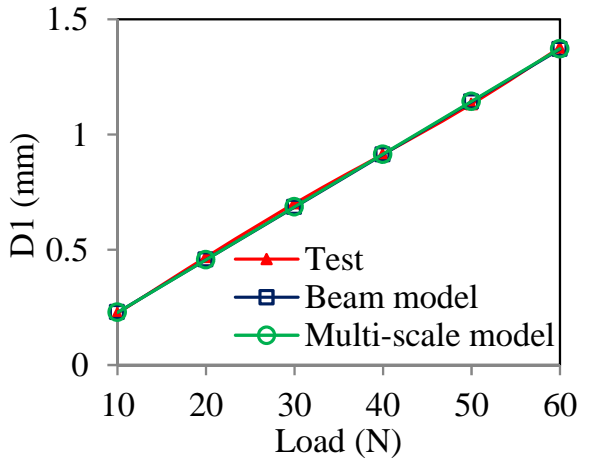

(a) D1

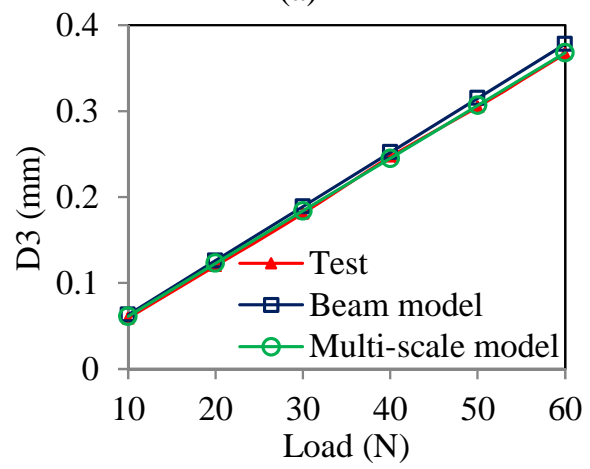

(c) D3

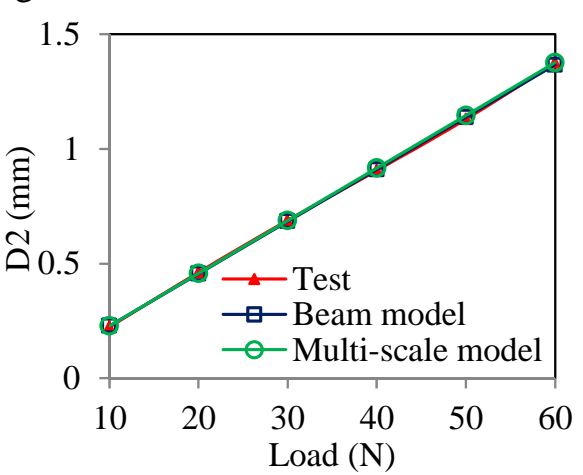

(b) D2

Figure 7. Force-displacement Relationship

The comparison results of the strain responses to the horizontal concentrated load of $60 \mathrm{~N}$ are listed in Table 2 for the main member of the tower leg. The strain results obtained from the multi-scale model are very close to the test results. For the strain responses of the main member of the tower leg, the multi-scale model and the beam model provide almost the same accuracy. The reason is that the measurement points on the tower leg are far away from the local joint modeled by the solid elements.

Figure 8 shows the locations of strain gauges on the gusset plate and the main member of the local joint, which are modeled in much detail using the solid elements in the multi-scale model of the tower. The equivalent strain used for the comparison of strain responses on the gusset plate is computed by

$$
\varepsilon_{e}=\frac{1}{1+v}\left[\frac{\left(\varepsilon_{1}-\varepsilon_{2}\right)^{2}+\left(\varepsilon_{2}-\varepsilon_{3}\right)^{2}+\left(\varepsilon_{3}-\varepsilon_{1}\right)^{2}}{2}\right]^{\frac{1}{2}}
$$

where $\varepsilon_{1}, \varepsilon_{2}$ and $\varepsilon_{3}$ are the principal strains; and $v$ is the effective Poisson's ratio. In the static test, the strain rosettes were used to measure the strain state of the gusset plate, and two principal strains are calculated from the measured strain state. Eq. (8) is then used to calculate the equivalent strain by combining the two principal strains obtained from the measured results of the strain rosette and a zero principal strain. 
The comparison results of strains of the local joint are listed in Table 3. It can be seen that the strain responses of the main member near the local joint (measurement points S13 and S14) calculated from the multi-scale model are more accurate than those from the beam model if the test results are referred. The maximum error by using the beam model and the multi-scale model are $99.51 \%$ and $4.65 \%$, respectively, with respect to the test results. From the test results of S13 and S14, it can be seen that the main member is under large bending moment caused by the bolt connection. However, the beam model built by rigid joints cannot simulate this bending moment caused by the bolt connection. Therefore, the errors in the strain responses of the main members connected to the local joint are very large if the beam model is used. The multi-scale model uses solid elements for modeling the local joint, which can effectively simulate the force transmission from the bolt connection. Therefore, the multi-scale model can obtain good accuracy for the strain responses of the main members connected to the local joint. Furthermore, the multi-scale model can obtain the strain responses of the gusset plate with good accuracy of the maximum error less than $7.90 \%$. From the comparison of the static responses of displacement and strain, it can be concluded that the multi-scale model can obtain more accurate strain and displacement responses at the region near the local joint modeled by the solid elements.

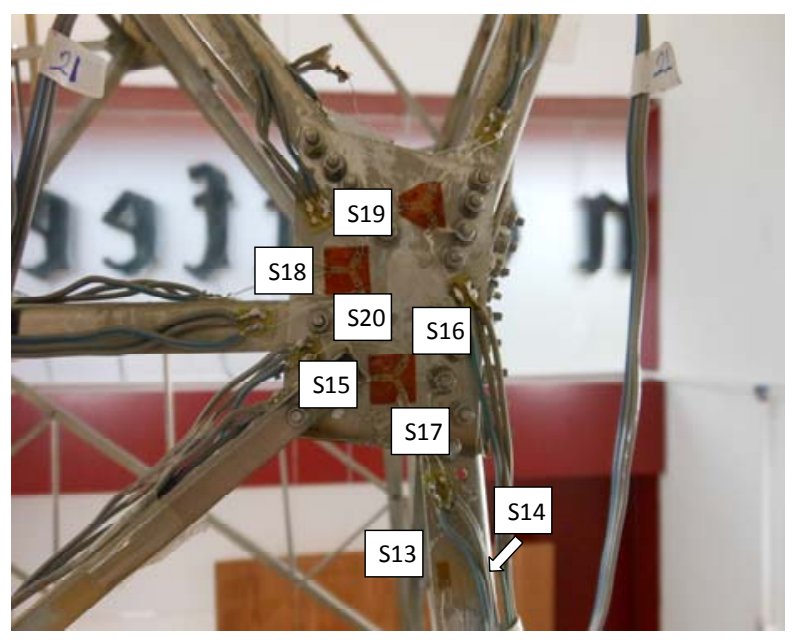

Figure 8. Locations of Strain Gauges on Local Joint

\subsection{Comparison of Dynamic Characteristics}

The modal analysis is carried out using the beam model and multi-scale model of the transmission tower. The natural frequencies are obtained and compared with the test results, as listed in Table 4. It can be seen that the maximum error using the multi-scale model occurs at the sixth natural frequency with a relative error of $5.41 \%$. The first, second and third mode shapes of the tower obtained from the multi-scale model are shown in Figure 9. It can be seen that the first mode of vibration is the translational mode mainly in the longitudinal direction. The second mode of vibration is also the translational mode but mainly in the transverse direction. The third mode of vibration is the torsional mode. The comparison of the first nine mode shapes from the multi-scale analysis (MSA) and the test are shown in Figure 10, in which the mode shapes are shown in different directions. The first, third, fourth, fifth and sixth order mode shapes are shown in the longitudinal direction, whereas the second, seventh, eighth and ninth order mode shapes are shown in the transverse direction. The first three mode shapes from the multi-scale analysis agree well with the test results. For other higher order mode shapes, some differences exist between the multi-scale analysis and the test. 


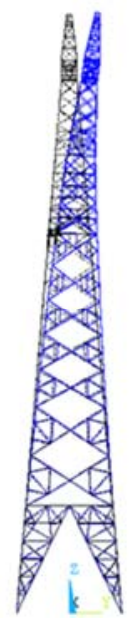

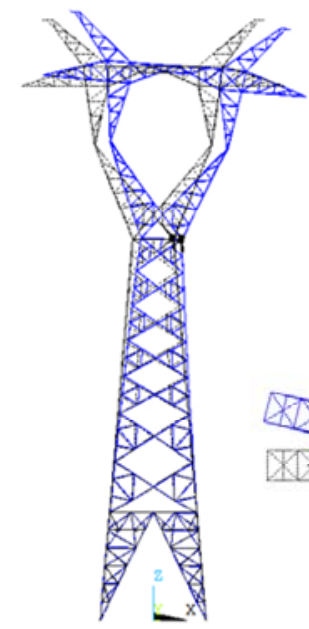

(b) second mode

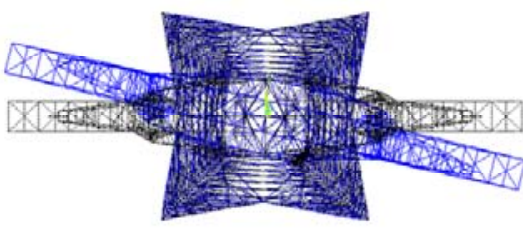

(a) first mode (view in X-direction) (view in Y-direction) (c) third mode

(view in Z-direction)

Figure 9. The First Three Mode Shapes of the Tower obtained from the Multi-scale Model

Table 4. Comparison of Natural Frequencies (Hz)

\begin{tabular}{ccccccc}
\hline $\begin{array}{c}\text { Mode } \\
\text { no. }\end{array}$ & $\begin{array}{c}\text { Mode shape } \\
\text { description }\end{array}$ & $\begin{array}{c}\text { Measured } \\
\text { frequency }\end{array}$ & $\begin{array}{c}\text { Beam } \\
\text { model }\end{array}$ & $\begin{array}{c}\text { Error } \\
(\%)\end{array}$ & $\begin{array}{c}\text { Multi-scale } \\
\text { model }\end{array}$ & $\begin{array}{c}\text { Error } \\
(\%)\end{array}$ \\
\hline 1 & $\begin{array}{c}\text { Longitudinal } \\
\text { bending }\end{array}$ & 16.56 & 16.39 & 1.03 & 16.38 & 1.09 \\
2 & $\begin{array}{c}\text { Transverse } \\
\text { bending }\end{array}$ & 16.81 & 16.46 & 2.08 & 16.44 & 2.20 \\
3 & $\begin{array}{c}\text { Torsion } \\
\text { Longitudinal } \\
\text { bending }\end{array}$ & 22.50 & 23.63 & 5.02 & 23.49 & 4.40 \\
4 & 44.36 & 44.40 & 0.09 & 44.40 & 0.09 \\
5 & $\begin{array}{c}\text { Longitudinal } \\
\text { bending } \\
\text { Longitudinal } \\
\text { bending }\end{array}$ & 44.50 & 44.62 & 0.27 & 44.63 & 0.29 \\
7 & $\begin{array}{c}\text { Transverse } \\
\text { bending }\end{array}$ & 52.30 & 53.56 & 2.41 & 53.62 & 2.52 \\
8 & $\begin{array}{c}\text { Transverse } \\
\text { bending }\end{array}$ & 59.83 & 57.54 & 3.83 & 57.58 & 3.76 \\
9 & $\begin{array}{c}\text { Transverse } \\
\text { bending }\end{array}$ & 60.56 & 57.72 & 4.69 & 57.75 & 4.64 \\
\hline
\end{tabular}

The Modal Assurance Criteria (MAC) is calculated as

$\operatorname{MAC}\left(\phi_{i}^{\text {test }}, \phi_{i}^{\text {FE }}\right)=\frac{\left(\phi_{i}^{\text {test }} \phi_{i}^{F E}\right)^{2}}{\left(\phi_{i}^{\text {test }} \phi_{i}^{\text {test }}\right)\left(\phi_{i}^{\text {FE }} \phi_{i}^{F E}\right)}$

where $\phi_{i}^{\text {test }}$ and $\phi_{i}^{F E}$ are the $i$ th mode shape from test and finite element analysis, respectively. The MAC values for the beam model and the multi-scale model are listed in Table 5. It can be seen that the multi-scale model and the beam model have almost the same accuracy for mode shapes. The similar natural frequencies and mode shapes from the beam model and the multi-scale model are understandable because the difference between the beam model and the multi-scale model is one local joint model in the multi-scale model, which does not affect the global dynamic characteristics of the tower. 


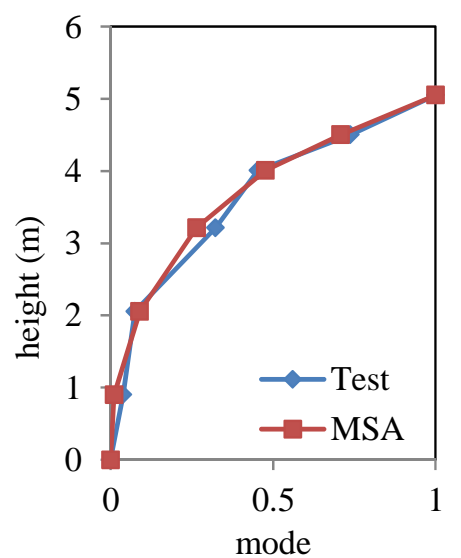

(a) first order mode

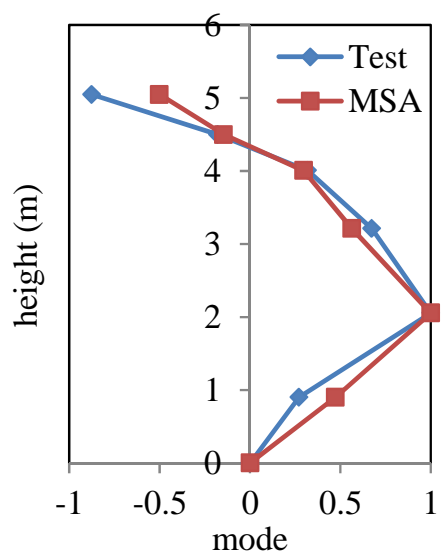

(d) fourth order mode

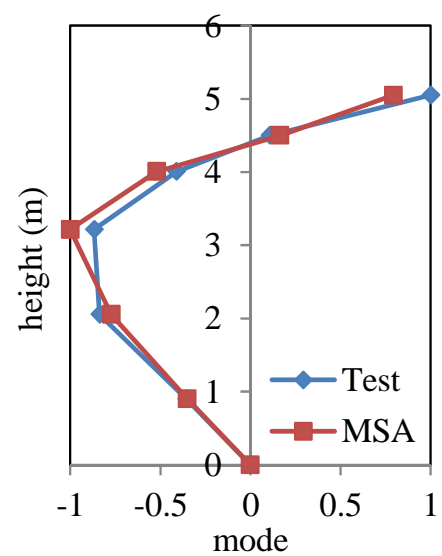

(g) seventh order mode

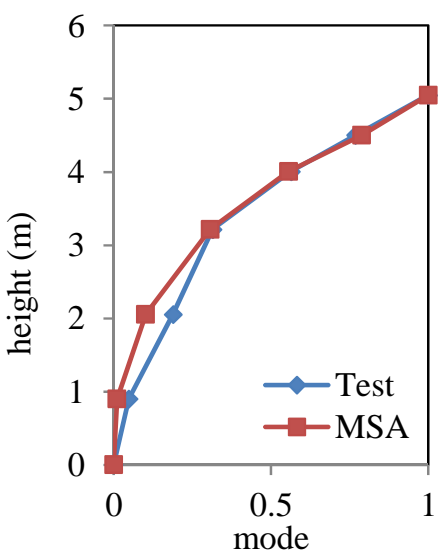

(b) second order mode

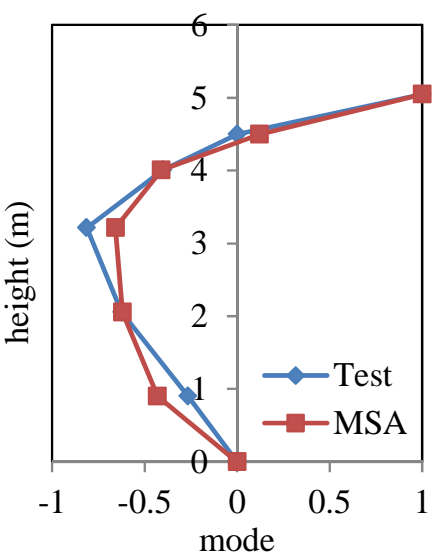

(e) fifth order mode

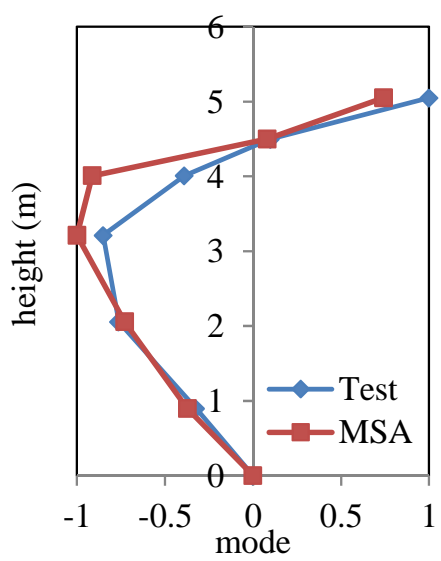

(h) eighth order mode

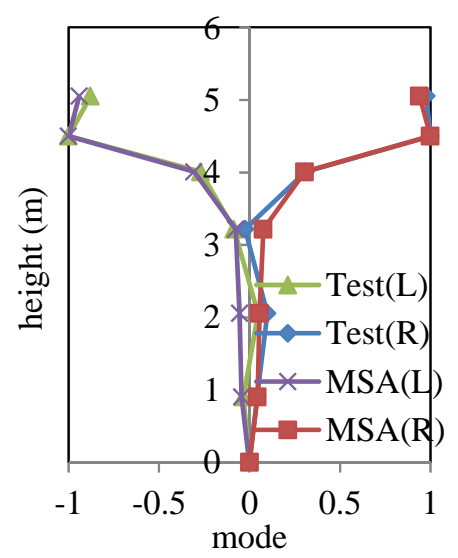

(c) third order mode

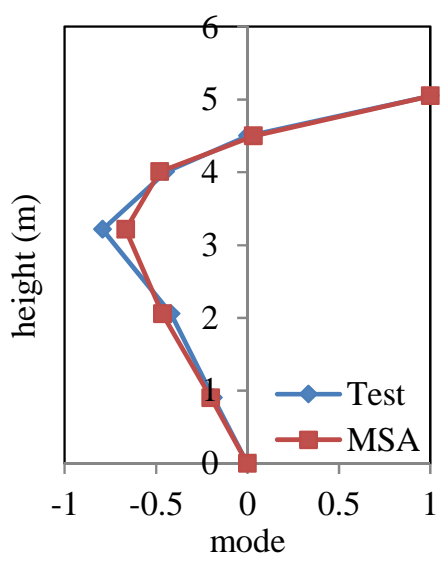

(f) sixth order mode

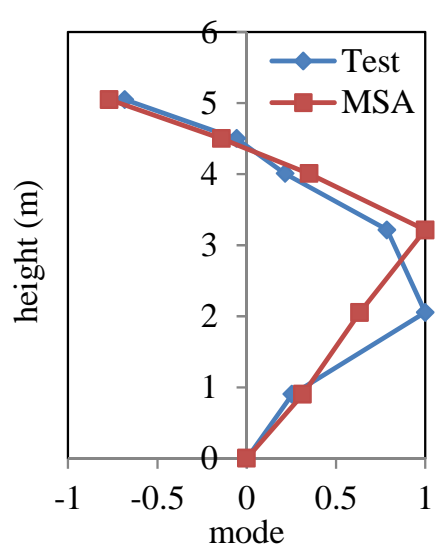

(i) ninth order mode

Figure 10. Comparison of the First Nine Mode Shapes from the Multi-scale Analysis and Test

Table 5. MAC of Modal Shapes

\begin{tabular}{cccccccccc}
\hline Mode number & 1 & 2 & 3 & 4 & 5 & 6 & 7 & 8 & 9 \\
\hline Beam model & 0.9939 & 0.9958 & 0.9936 & 0.9407 & 0.9653 & 0.9889 & 0.9741 & 0.9089 & 0.9107 \\
Multi-scale model & 0.9940 & 0.9958 & 0.9935 & 0.9377 & 0.9664 & 0.9897 & 0.9719 & 0.9104 & 0.9075 \\
\hline
\end{tabular}




\section{CONCLUSIONS}

The multi-scale modeling method has been developed for the simultaneous global and local analysis of a transmission tower structure with bolt connections. The solid elements are used to model the bolted-connection joint that includes angle members, gusset plates and bolts. All other joints are modeled as rigid joints and all other angle members are modeled by the beam elements. A physical model of the transmission tower has been constructed and tested. The calculated results from the multi-scale model and the beam model are compared with those from the tests. The comparative results demonstrate that the calculated displacement responses from the multi-scale model and the beam model are very close to the measured ones if the locations of the concerned displacements are away from the flexible joint modeled by the solid elements. The calculated natural frequencies and mode shapes from the multi-scale model and the beam model are also close to the measured ones. Compared with the beam model, the multi-scale model can obtain more accurate strain and displacement responses of the members connected to the local joint that is modeled by the solid elements. By using the solid elements for modeling the local joint, the multi-scale model effectively simulates the force transmission of bolt connections and provides good accuracy for the strain responses of the main members connected to the local joint modeled by the solid elements. The multi-scale modeling method has great advantages of improving the accuracy of local responses for the large transmission tower.

\section{ACKNOWLEDGMENTS}

The work described in this paper is financially supported by The Hong Kong Research Grants Council through its competitive grant (PolyU 5289/12E) and by the Natural Science Foundation of China through its key research program (NSFC 50830203), to which the authors are grateful.

\section{REFERENCES}

[1] Albermani, F.G.A. and Kitipornchai, S., "Numerical Simulation of Structural Behaviour of Transmission Towers", Thin-walled Structures, 2003, Vol. 41, No. 2-3, pp. 167-177.

[2] Chan, S.L. and Cho, S.H., "Second-order Analysis and Design of Angle Trusses Part I: Elastic Analysis and Design", Engineering Structures, 2008, Vol. 30, No. 3, pp. 616-625.

[3] Rao, N.P., Knight, G.M.S., Lakshmanan, N. and Iyer, N.R., "Investigation of Transmission Line Tower Failures", Engineering Failure Analysis, 2010, Vol. 17, No. 5, pp. 1127-1141.

[4] Roy, S., Fang, S.J. and Rossow, E.C., "Secondary Stresses on Transmission Tower Structures", Journal Of Energy Engineering-Asce, 1984, Vol. 110, No. 2, pp. 157-172.

[5] Rao, N.P. and Kalyanaraman, V., "Non-linear Behaviour of Lattice Panel of Angle Towers", Journal of Constructional Steel Research, 2001, Vol. 57, No. 12, pp. 1337-1357.

[6] Jiang, W.Q., Wang, Z.Q., McClure, G., Wang, G.L. and Geng, J.D., "Accurate Modeling of Joint Effects in Lattice Transmission Towers", Engineering Structures, 2011, Vol. 33, No. 5, pp. 1817-1827.

[7] Kitipornchai, S., Albermani, F.G.A. and Peyrot, A.H., "Effect Of Bolt Slippage on Ultimate Behavior Of Lattice Structures", Journal Of Structural Engineering, 1994, Vol. 120, No. 8, pp. 2281-2287.

[8] Knight, G.M.S. and Santhakumar, A.R., "Joint Effects on Behavior Of Transmission Towers", Journal Of Structural Engineering, 1993, Vol. 119, No. 3, pp. 698-712.

[9] Xu, Y.L. and Zhang, W.S., "Modal analysis and seismic response of steel frames with connection dampers", Engineering Structures, 2001, Vol. 23, No. 4, pp. 385-396. 
[10] Ungkurapinan, N., Chandrakeerthy, S.R.D., Rajapakse, R.K.N.D. and Yue, S.B., "Joint Slip in Steel Electric Transmission Towers", Engineering Structures, 2003, Vol. 25, No. 6, pp. 779-788.

[11] Cheng, J.J.R., Yam, M.C.H. and Hu, S.Z., "Elastic Buckling Strength Of Gusset Plate Connections", Journal of Structural Engineering, 1994, Vol. 120, No. 2, pp. 538-559.

[12] Rosenstrauch, P.L., Sanayei, M. and Brenner, B.R., "Capacity Analysis of Gusset Plate Connections using the Whitmore, Block Shear, Global Section Shear, and Finite Element Methods", Engineering Structures, 2013, Vol. 48, No. 1, pp. 543-557.

[13] Salih, E.L., Gardner, L. and Nethercot, D.A., "Bearing Failure in Stainless Steel Bolted Connections", Engineering Structures, 2011, Vol. 33, No. 2, pp. 549-562.

[14] Salih, E.L., Gardner, L. and Nethercot, D.A., "Numerical Study of Stainless Steel Gusset Plate Connections", Engineering Structures, 2013, Vol. 49, No. 1, pp. 448-464.

[15] Li, Z.X., Chan, T.H.T., Yu, Y. and Sun, Z.H., "Concurrent Multi-scale Modeling of Civil Infrastructures for Analyses on Structural Deterioration-Part I: Modeling Methodology and Strategy", Finite Elements in Analysis and Design, 2009, Vol. 45, No. 11, pp. 782-794.

[16] Dujc, J., Brank, B. and Ibrahimbegovic, A., "Multi-scale Computational Model for Failure Analysis of Metal Frames that Includes Softening and Local Buckling", Computer Methods in Applied Mechanics and Engineering, 2010, Vol. 199, No. 21-22, pp. 1371-1385.

[17] Li, Z.X., Zhou, T.Q., Chan, T.H.T. and Yu, Y., "Multi-scale Numerical Analysis on Dynamic Response and Local Damage in Long-span Bridges", Engineering Structures, 2007, Vol. 29, No. 7, pp. 1507-1524.

[18] Guidault, P.A. and Belytschko, T., "On the L2 and the H1 Couplings for An Overlapping Domain Decomposition Method using Lagrange Multipliers", International Journal for Numerical Methods in Engineering, 2007, Vol. 70, No. 3, pp. 322-350.

[19] Ben Dhia, H. and Rateau, G., "The Arlequin Method as a Flexible Engineering Design Tool", International Journal for Numerical Methods In Engineering, 2005, Vol. 62, No. 11, pp. 1442-1462.

[20] Xu, F., Hu, H., Potier-Ferry, M. and Belouettar, S., "Bridging Techniques in a Multi-scale Modeling of Pattern Formation", International Journal of Solids and Structures, 2014, Vol. 51, No. 18, pp. 3119-3134.

[21] Bauman, P.T., Dhia, H.B., Elkhodja, N., Oden, J.T. and Prudhomme, S., "On the Application of the Arlequin Method to the Coupling of Particle and Continuum Models", Computational Mechanics, 2008, Vol. 42, No. 4, pp. 511-530.

[22] Wellmann, C. and Wriggers, P., "A Two-scale Model of Granular Materials", Computer Methods in Applied Mechanics and Engineering, 2012, Vol. 205, No. 1, pp. 46-58.

[23] Cofer, W.F. and Will, K.M., "A Three-dimensional, Shell-solid Transition Element for General Nonlinear Analysis", Computers \& Structures, 1991, Vol. 38, No. 4, pp. 449-462.

[24] Garusi, E. and Tralli, A., "A Hybrid Stress-assumed Transition Element for Solid-to-beam and Plate-to-beam Connections", Computers \& Structures, 2002, Vol. 80, No. 2, pp. 105-115.

[25] Gmür, T.C. and Kauten, R.H., "Three-dimensional Solid-to-beam Transition Elements for Structural Dynamics Analysis", International Journal for Numerical Methods in Engineering, 1993, Vol. 36, No. 9, pp. 1429-1444.

[26] Chavan, K.S. and Wriggers, P., "Consistent Coupling of Beam and Shell Models for Thermo-elastic Analysis", International Journal for Numerical Methods in Engineering, 2004, Vol. 59, No. 14, pp. 1861-1878.

[27] Ho, R.J., Meguid, S.A., Zhu, Z.H. and Sauve, R.G., "Consistent Element Coupling in Nonlinear Static and Dynamic Analyses using Explicit Solvers", International Journal of Mechanics and Materials in Design, 2010, Vol. 6, No. 4, pp. 319-330. 
[28] McCune, R.W., Armstrong, C.G. and Robinson, D.J., "Mixed-dimensional Coupling in Finite Element Models", International Journal For Numerical Methods In Engineering, 2000, Vol. 49, No. 6, pp. 725-750.

[29] Wang, J.L.W., Lou, Z.W., Min, X. and Zou, J.Z., "A DOF Expanding Method for Connecting Solid and Shell Element", Communications In Numerical Methods In Engineering, 1996, Vol. 12, No. 6, pp. 321-330.

[30] Wang, F.Y., Xu, Y.L. and Qu, W.L., "Mixed-dimensional Finite Element Coupling for Structural Multi-scale Simulation", Finite Elements in Analysis and Design, 2014, Vol. 92, No. 1, pp. 12-25.

[31] ANSYS, "User's Manual", ANSYS. Inc., 2010. 